\title{
CASE: UNUSUAL MIGRATION OF OSTEOSYNTHETIC MATERIAL
}

\author{
Petr Habal', Václav Málek², Josef Novotny ${ }^{3}$
}

Charles University in Prague, Faculty of Medicine in Hradec Králové and University Hospital Hradec Králové: Department of Cardiosurgery ${ }^{1}$, Department of Neurosurgery ${ }^{2}$, Department of Radiology ${ }^{3}$

Summary: The authors present a rare and unusual case of complication, migration of osteosynthetic material for stabilization, titanium rod, which was used for stabilization of comminutive fracture of the first lumbar vertebra. This rod migrated from the retroperitoneal space to the pleural cavity. The removal of this rod was carried out by videothoracoscopy.

Key words: Foreign body migration; Backbone stabilization; Videothoracoscopy

\section{Introduction}

In many surgical disciplines, mainly in those which deal with skeletal trauma, there are used different metal devices for stabilizing purposes. Because of various unpredictable situations, migration of such devices into body cavities and organs might happen. Removal of such migrating devices is necessary since they might cause injury especially to the parenchymal organs. The methods of removal are various but the endoscopical ones are those more and more preferred.

\section{Case description}

A 50-year-old man fell on his back from the height of 5 meters on a concrete floor. There was not loss of conciousness but he sustained multiple fractures of both upper extremities. In the first instance he was treated in the local surgical site, where he complained about tingling in his lower extremities without mobility limitations. Plain radiography revealed multiple dislocated fractures of both bones of right forearm, serial fractures of ribs bilaterally in the range of 3-6 ribbs with a small dislocation of fragments. There were neither pneumothorax nor hemothorax. The ultrasound examination of peritoneal cavity did not reveal any contusion of parenchymatous organs. There was no hemoperitoneum. The most serious injury was imaged on the CT examination of the backbone. Due to the fall on the patient's back a burst fracture of first lumbar vertebra with break off of one third of vertebral body and abruption of transversal processus on the left side emerged. Some of fragments moved ventrally to the vertebral canal, which was subsequently narrowed, but neither spinal cord nor dura mater were injured. After the stabilization of vital functions of otherwise spontaneously ventilating patient he was transferred to the neurosurgical department. The ope- ration was carried out 11 hours after the injury. Quotation from operational records in neurosurgical dept.: ,in the first phase of operation carried from dorsal path after uncovering of transversal processes Th12-L2 there were inserted transpedicular screws $6 \times 60 \mathrm{~mm}$ into Th12-L2 bilaterally. By means of a repositional device called Socon the dorsal wall of vertebrae was adjusted and subsequently due to lordotization the ventral wall of vertebrae was adjusted as well.

In the second phase, following 14 days period after the first operation another resection of ventral plane of vertebra L1 with removal of intervertebral discs Th12/L1 and L1/2 was carried out from left-sided lumbotomy via retroperitoneal access. The body of destructed L1 vertebra was due to previous reposition very well expanded but the ventral part of the vertebra was broken off. Vertebral body was reconstructed with help of tricortical bone graft from left iliac bone. The whole reconstruction was overbridged by anterolateral stabilization WBR Biomet Merck“, the end of quotation. Postoperational course was favourable, the patient was early rehabilitated in Jewet jacket and on the $10^{\text {th }}$ postoperational day was transferred to the local surgical site for aftertreatment and rehabilitation without any neurological defect.

After 3 months of intensive rehabilitation, there was a checking examination carried out in neurosurgical outpatient department and the patient was complaining of pain of stabbing and pressure character in the region of lower thoracic aperture on the left side. The patient himself explained this pain by intensive rehabilitation. Repeated plain film of lumbar spine revealed the correct position of the spine (Fig. 1). Surprising additional finding which explained subjective troubles of the patient was the finding of a titanium stabilizing rod in the left pleural cavity (Fig. 2). $\mathrm{CT}$ and subsequently made reconstruction showed foreign body lying tightly above the dome of diaphragm in poste- 
rior costophrenic angle (Fig. 2,3). The patient was transferred to the cardiosurgery department for additional treatment.

Following usual preoperative preparation and intubation with double lumen tube we collapsed left lung and having patient positioned on his right decubitus we introduced a port for videothoracoscopy device in the 4th intercostal space in the middle axial line. In the left pleural cavity we discovered a titanium rod freely lying in posterior costophrenic angle on the dome of diaphragm (Fig. 4). We searched carefully for any diaphragmatic injury, especially in insertions of diaphragm to the thoracic wall and in posterior costophrenic angle but we did not discover any defect

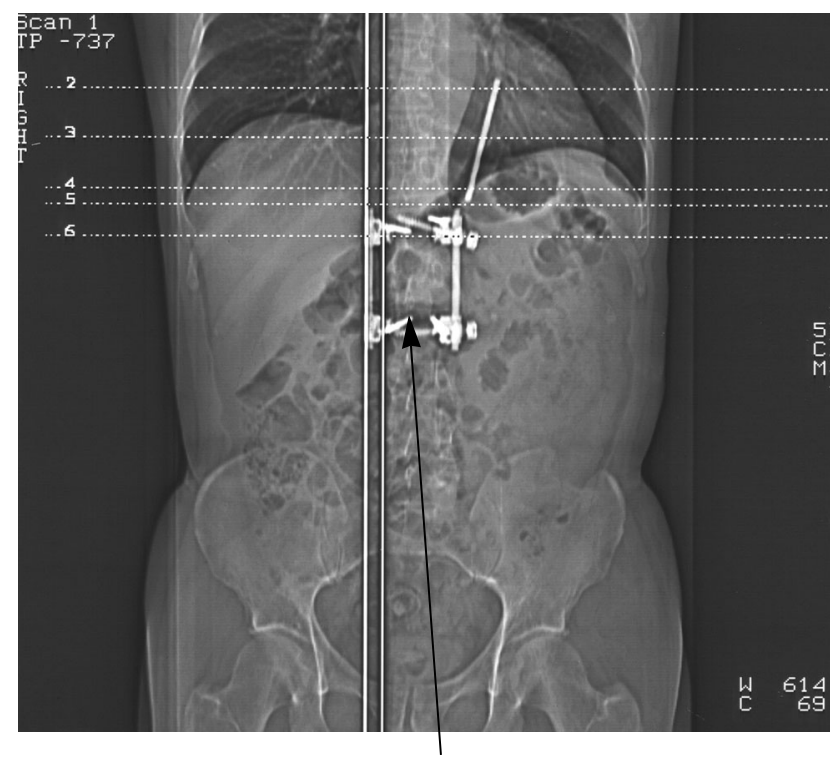

Fig. 1: Toposcan: Correct position of the spine.

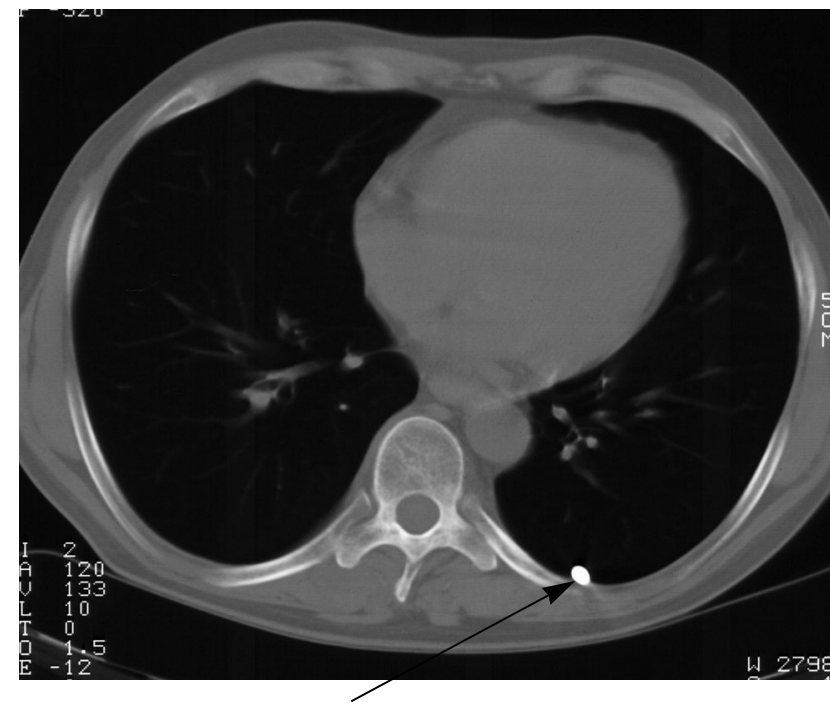

Fig. 3: CT showed foreing body in posterior costophrenic angle. estimated as a foreign body entrance. We inserted the second port in the posterior axilar line in the 6 th intercostal space and by means of endoscopic instrumentarium we extracted the iron rod via $20 \mathrm{~mm}$ port (Fig. 5,6). We inserted a thoracic drain via the frontal port and then the anestesiologist expanded the collapsed lung under the videothoracic control. Postoperational course was without any complications, overall drain blood discharge was $150 \mathrm{ml}$. The drain was extracted on the 2 nd postoperational day. The patient was discharged on the 5th postoperational day to home care and transferred back to the neurosurgery outpatient care. In our control outpatient examination after 3 months he was fully rehabilitated and without complaints.

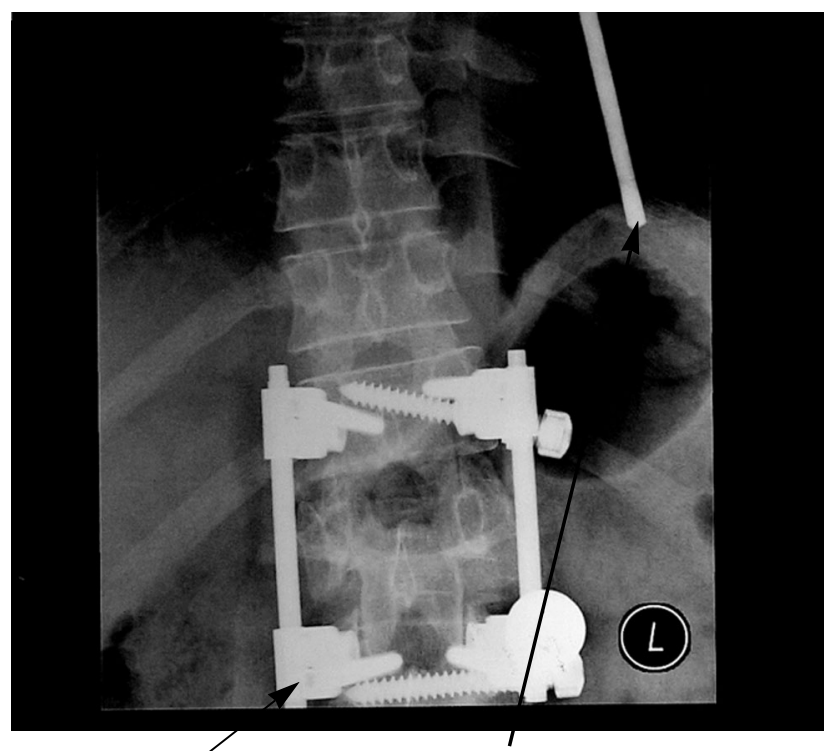

Fig. 2: Backbone stabilization, titanium rod in the left pleural cavity.

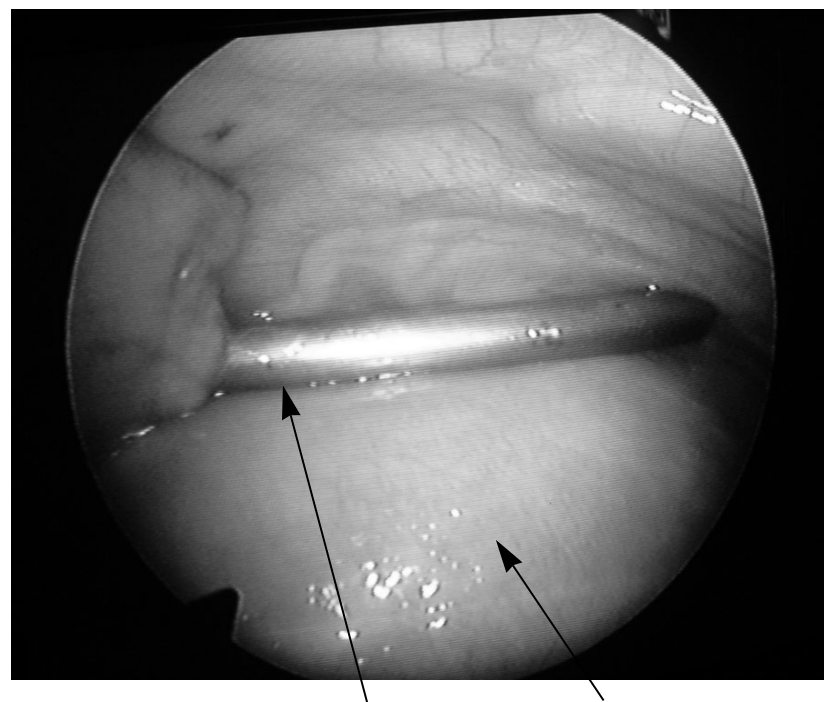

Fig. 4: VTS showed the rod on the dome of diaphragm.cavity. 


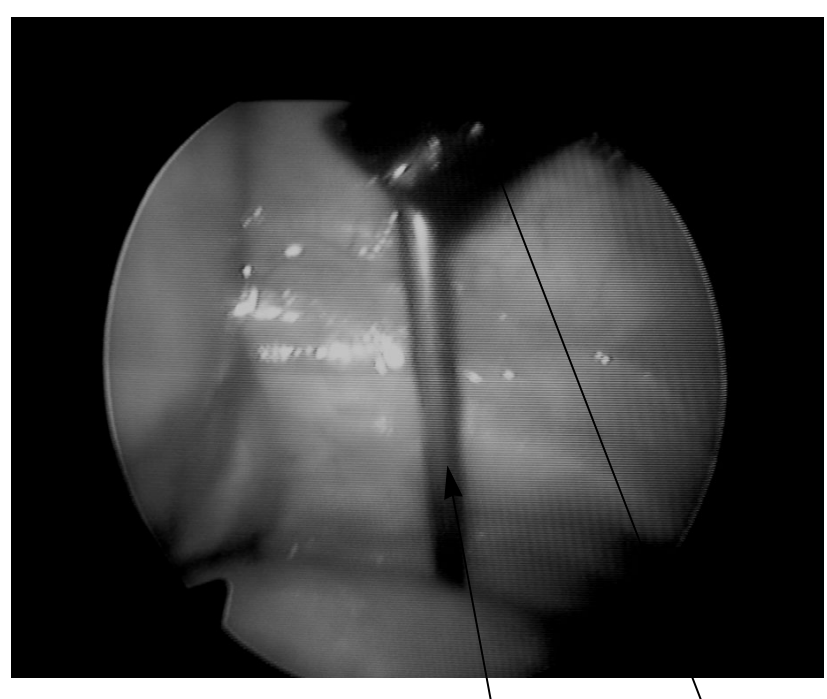

Fig. 5: VTS: We extracted the titanium rod via $20 \mathrm{~mm}$ port.

\section{Discussion}

During the treatment of the backbone fractures it is necessary to secure the reposition and stabilization of the fracture and the reconstruction of the backbone to reach anatomical proportions and a good function of the backbone in the future. The reposition and stabilization are performed by means of instrumentation in $70-80 \%$ of cases from the dorsal path. In about $20 \%$ of cases, if the reconstruction of the ventral backbone column is necessary, a combined approach is needed, usually in two phases. In the first phase, usually acute, a dorsal reposition is performed to prevent a possible injury of the spinal cord. The second phase from the ventral path is planned in an interval of 10-14 days in the rest stage (6). The treatment of the ventral backbone column is maintained in different ways, but all of them must ensure a solid osseous fusion of injured vertebras. It is possible to use Harms cage fulfilled with bone debris or to substitute the vertebral body (Synex, Biomed cage etc.). The choice of the method depends on the habits and economical potential of the department. The Xray controls are routinely performed after the stabilization operation, before the verticalization of the patient, before the dismissal of the patient, and 3, 6 and 12 months after the cessation of the operating treatment.

The most common and in the literature described are migrations of Kirschner wire, which is used for stabilization of clavicular fractures and for osteosyntheses in the region of shoulder. The Kirschner wires can loosen sometimes without any explainable reason and they can travel either per continuitatem into the pleural cavity or to the lung parenchyma $(7,8)$. According to the literature, this eventuality is mentioned in up to $5,4 \%$ (4). Another case, described in the literature as well, could be the migration of the wire into lumen of vein with the possibility of travelling into the right cardiac chamber $(2,9)$. Such really rare cases could be ex-

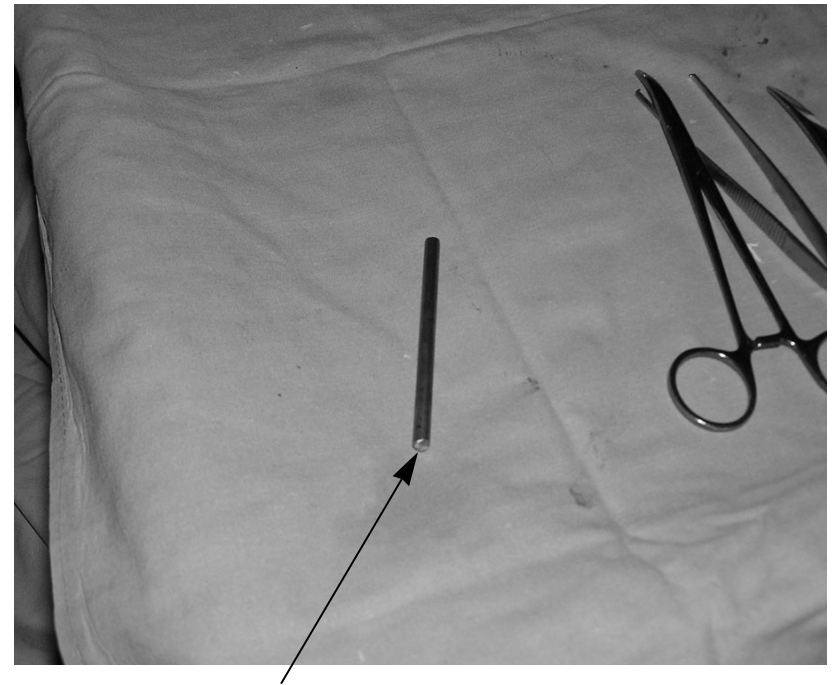

Fig. 6: Titanium rod $90 \mathrm{~mm}$.

plained by injury of the wall of the subclavian vein during the operation. The subclavian vein is supposed to be very closely bound by hematoma to the clavicule in the place of the fracture. Our case seems to be extremely rare because in the available literature there are no similar cases reported. There is only one case of transdiaphragmatic migration of ventriculoperitoneal cathether into the right pleural cavity in 3-year-old child with hydrocephalus, 3 years after the placement of this drainage (5). In our case, the eventuality of injury in costophrenic angle was excluded during the thoracoscopy.

Our case is probably explainable by very oblique ribs position during the retroperitoneal approach and therefore very difficult setting of fixating nut. They were probably incorrectly positioned on the screw thread and therefore incorrectly tighten despite the special spanner was used.

\section{Conclusion}

There is little personal experience with migration of foreign bodies and so the information about it is obtained only from the literature. One can be advised how to avoid such situations dealing with Kirschner wire. There must be correct decision about usage and appropriate application with close attention to the loose flexed end of wire which has to be checked in the course of treatment. Osteosynthetic material should be extracted as soon as possible. The removal of Kirschner wires out of clavicule and shoulder is relatively easy. On the other hand, the removal of material from spine stabilizing positions would be a significant burden for the patients. In these locations it is better to prevent such situations by choosing combined thoraco-retroperitoneal access rather than a retroperitoneal one which does not allow good peroperational overview. Based on our reported experience we prefer such combined approach despite 
there is necessity to separate diaphragmatic attachements in the region of posterior costophrenic angle.

After all if such a rare complication happens, there is an effort to burden the patient as little as possible not only for medical reasons but also to prevent any medicolegal complaints. The best way to solve such a complication is the usage of endoscopic device. The history of the use of thoracoscopy reaches to the beginning of last century. It is interesting that the first usage of thoracoscope for observation thoracic cavity was carried out by the professor of internal medicine Hans Christian Jacobeus in pulmonary sanatorium in Sweden in 1910 (1). Currently the thoracoscopy is mainly used in the diagnostics of processes in thoracal cavity, pneumothorax treatment and benign processes of lungs and pleura. It is less used for radical cure of bronchogenic carcinoma because there is an effort not only to anatomically resect lung but also to carry out mediastinal lymphadenectomy, which leads not only to better survival but also allows the correct staging of tumour. Statistical works denote the usage of thoracoscopy for diagnostic purposes in about $50 \%$ (3). In thoracic traumatology, there are some departments that use thoracoscopy for the observation of pleural cavity before thoracotomy. In our department, because of time reasons, we prefer to use directly thoracotomy. For the extraction of foreign bodies this method is very advantageous though not entirely common.

\section{References}

Jacoubeus HC. The practical improtance of thoracoscopy in surgery of the chest. Surg Gynecol Obstet 1921;32:493-500.

2. Knott-Craig CJ, Dalton RP, Rossouw GJ et al. Penetrating cardiac trauma: Management strategy based on 129 surgical emergencies over 2 years. Ann Thorac Surg 1992;53:1006-89.

3. Larry R, Kaiser. Video-assisted thoracic surgery. Ann Surg 1994;220:720-34.

4. Lawson JA, Bender J. Migration of Kirschner wire from the right hip to the left lung. Ned Tijdscher Geneeskd 1971;121(43):1706-10.

5. Lourie H, Bajwa S. Transdiaphragmatic migration of a ventriculoperitoneal catheter. Neurosergery 1998;517(2):324-6.

6. McCormac T, Karaikovic E, Gaines RW. The load sharing classification of spine fractures. Spine 1994;19(15):1741-4.

7. Pafko P, Franek J. Př́ípad vycestování Kirschnerova drátu do plíce. Pozhl Chir 1988;67(4):276-8.

8. Starke W, Schilling H. Kirschnerdrahtwanderung nach osteosynthesen. Aktuel Traumatol 1998;11(14):126-9.

9. Šimek J, Žáček P, Vacek Z. Neobvyklá komplikace osteosyntézy. Acta Med (Hradec Králové) Suppl 2002;45(2):58-7.

Submitted November 2004.

Accepted January 2005.

MUDr. Petr Habal,

University Hospital Hradec Králové, Department of Cardiosurgery, 50005 Hradec Králové, Czech Republic. e-mail:phabal@seznam.cz 